\title{
Representaciones sociales a través del lenguaje en la lexicografía hispanoamericana decimonónica
}

\author{
José Carlos Huisa Téllez ${ }^{*}$ \\ Johannes Gutenberg-Universität Mainz, Alemania
}

Resumen

Este artículo parte de una propuesta de análisis relativamente reciente de la primera lexicografía hispanoamericana después de la independencia, que consiste en asumir una estrecha relación entre la elaboración, difusión y recepción de los primeros diccionarios del español americano -en cuanto producción cultural de la elite criolla-, y los procesos históricos y socio-políticos de la época. Sobre esta base, se postula la existencia de una unidad del discurso lexicográfico, a pesar de la diversidad de obras y autores, que es posible entrever y caracterizar. Se analizan, en consecuencia, los mecanismos que en este discurso se ponen en funcionamiento para ofrecer representaciones sociales -en el plano político y en el puramente social-, cuyo papel en una época de formación nacional es definitorio. Tal análisis se ejemplifica con la lectura y comparación de las dos obras más características, el Diccionario de chilenismos (1875) de Zorobabel Rodríguez y el Diccionario de peruanismos. Ensayo filológico (1883-84) de Juan de Arona.

Para correspondencia, dirigirse a: José Carlos Huisa Téllez (huisaj@uni-mainz.de), Johannes Gutenberg-Universität Mainz, Welder Weg 18, 55099 Mainz, Alemania. 
Palabras clave: diccionario de chilenismos, diccionario de peruanismos, formación nacional, Juan de Arona, lexicografía hispanoamericana, representaciones sociales, Zorobabel Rodríguez.

\title{
SOCIAL REPRESENTATIONS THROUGH LANGUAGE IN 19TH CENTURY
}

SPANISH AMERICAN LEXICOGRAPHY

\begin{abstract}
This article departs from a fairly recent approach to the analysis of the first Hispano-American lexicography after the independence from Spain, consisting in a close relation between contemporary historical and socio-political processes and the elaboration, diffusion and reception of the first dictionaries of American Spanish, cultural products created by the creole elite. On this basis, a general unity of lexicographic discourse, despite the visible and described diversity in works and authors, is proven. Consequently, the use of social and socio-political representations, whose role is defining in nationbuilding, is analyzed. The proposed analysis is exemplified by the reading and comparison of the two most representative works, the Diccionario de chilenismos (1875) by Zorobabel Rodríguez and the Diccionario de peruanismos. Ensayo filológico (1883-84) by Juan de Arona.
\end{abstract}

Keywords: dictionary of chilenisms, dictionary of peruanisms, national formation, Juan de Arona, Spanish American lexicography, social representations, Zorobabel Rodríguez.

Recibido: 11/05/14 Aceptado: $17 / 08 / 14$

\section{INTRODUCCIÓN: EL ESTUDIO ACTUAL DE LA LEXICOGRAFÍA HISPANOAMERICANA DEL SIGLO XIX}

La atención prestada por la filología actual a las obras lexicográficas del español americano elaboradas en el siglo XIX se escinde en dos percepciones claramente contrapuestas. Por un lado, los criterios metodológicos seguidos por los primeros autores siguen siendo utilizados en gran medida en la práctica diccionarística sin que se plantee previamente ninguna reelaboración teórica que apunte a los objetivos que un diccionario del siglo XXI debe plantearse 
en cuanto obra de consulta ${ }^{1}$. Se repiten, así, principios ya fosilizados por el paso del tiempo, por ejemplo, el hecho de tomar como punto de referencia el diccionario académico para decidir qué elementos léxicos se registrarán o no, y la acumulación indiscriminada del mayor número de unidades sin importar su nivel de frecuencia o de uso actual. Todavía se piensa, por lo demás, que los diccionarios de este tipo están íntimamente relacionados con el orgullo y la identidad supuestamente nacionales de los hablantes de la variante regional registrada. La segunda perspectiva es de signo completamente contrario y constituye una reacción a la situación que acabamos de señalar. Se parte aquí de la certidumbre de que la primera lexicografía hispanoamericana corporeiza la elección de un modelo por completo inadecuado, tanto en su época como con mayor razón en la actualidad, porque posterga un modelo integral que no parte de la comparación entre el habla propia y un español general o peninsular, comparación originada, según esta reflexión, por la aceptación tácita de la diferencia e inferioridad de los dialectos americanos frente al de la exmetrópoli ${ }^{2}$.

Esta segunda postura científica frente a los orígenes de la lexicografía hispanoamericana, cuya evaluación es pertinente para este trabajo, deja de lado dos cuestiones esenciales en el plano historiográfico: en primer lugar, la situación del español americano en el siglo XIX -en cuanto resultado del trasplante de la lengua y de su contacto con otras indígenas- que atraviesa, a partir del hecho histórico de la independencia, un proceso todavía poco estudiado de configuración de normas nacionales antes inexistentes, gracias al cual, por cierto, se hizo visible la variación que los diccionarios registran. En segundo lugar, se descuida el hecho de que esta primera lexicografía surge en medio de un proceso de formación nacional, del que constituye finalmente una clara manifestación, lo que no solo explicaría el registro de elementos propios de un determinado país -los llamados -ismos-, sino también las características estructurales de los mismos diccionarios. Al prestarle atención a estos dos elementos, la explicación y evaluación del fenómeno lexicográfico hispanoamericano se amplían a horizontes que el investigador antes no había entrevisto.

Una de las preguntas que desde este punto de vista el investigador debe plantearse se vincula íntimamente con la noción de discurso y la relación

Claras excepciones son aquellos proyectos de largo aliento que se dedican a la lexicografía integral, como el que dirige Luis Fernando Lara en El Colegio de México, y a una moderna lexicografía diferencial-contrastiva, llevada a cabo en concreto por el equipo de Reinhold Werner en la Universidad de Augsburgo en Alemania.

2 Ver, especialmente, Lara (1990). 
dialéctica que este mantiene con la sociedad, no solo en cuanto a temas lingüísticos en sí mismos sino especialmente en cuanto a la manera en que por medio de estos se filtran representaciones en un plano social. Siguiendo tal desiderata, revisaremos a continuación de qué forma el ambiente sociopolítico en una época de formación nacional jugó un papel decisivo en la elaboración de los diccionarios y qué tipo de representaciones sociales encontramos en ellos a partir de aquel. Nos serviremos para la presentación de ejemplos de los dos casos más prototípicos de la serie de obras a las que nos referimos: el Diccionario de chilenismos (1875) de Zorobabel Rodríguez y el Diccionario de peruanismos. Ensayo filológico (1883-84) de Juan de Arona.

\section{LA FORMACIÓN NACIONAL COMO FACTOR DECISIVO}

La variación del léxico del español americano frente al peninsular y a lo largo del continente ya era visible mucho antes del siglo XIX. La novedad en la lexicografía posterior a la independencia es el punto de referencia para el registro de las unidades léxicas que establecen los autores, esto es, los países recién constituidos, cuestión que nos induce a determinar algunas pautas para la crítica de esta práctica, las que mencionamos a continuación.

Debido a la determinación de los países como punto de referencia, estos primeros diccionarios constituyen el resultado de un primer impulso patriótico, lo que se expresa directamente en sus páginas, no solo en las palabras preliminares sino también en el mismo cuerpo lexicográfico. Dice Arona - para poner un ejemplo- ya en las primeras palabras de su trabajo: "Su autor la empezó [la obra] en Lóndres por los años de 1860, cuando aunados los recuerdos de la pátria y la vivacidad de sentimientos de los veinte años, buscaban en todo forma para manifestarse" (V). En el caso de Zorobabel Rodríguez, la situación es todavía más clara: como parte de un objetivo mayor de mejora del país, al inicio de su obra plantea el objetivo pedagógico de ella en el marco de la recién instaurada república.

También debemos reparar en una clara formación identitaria que se lleva a cabo de la mano de una descripción filológica; así, se asume y se fortalece la idea de un español de los peruanos, por ejemplo, que da por hecha la idea de una entidad en teoría bien determinada, los peruanos. Tender decididamente -en el plano de la lengua pero también en el social- a una homogeneización interna en cada país y a una diferenciación con el resto de países es consustancial a este proceso. Sintomático resulta que la elaboración 
del primer diccionario general de americanismos -el de Malaret de 1925fuera posterior y tuviera un manifiesto objetivo filológico.

No es difícil pensar, siguiendo este orden de ideas, en un tinte ideológico que se filtra en el registro lexicográfico decimonónico, lo que conlleva asumir la existencia de ideas nacionales o nacionalistas como base que sostenía esta práctica, no solo en el sentido que la historiografía tradicional ha concluido - esto es, especialmente, el orgullo nacional como impulso del registro de peculiaridades léxicas propias- sino también en el sentido estrechamente relacionado con la formación concreta y real de una nación que se reconoce como correlato de una comunidad determinada claramente y de un Estado recién fundado, de tal manera que resalte la modelación de las sociedades en los inicios de la época independiente.

No olvidemos, por otro lado, que en este marco se integran también elementos propios de la lexicografía de regionalismos. Uno de ellos es la normatividad -justificada en su época por el temor a la pérdida de la unidad idiomática, proveniente, a su vez, del paradigma biologicista al uso-, de lo que resulta una lexicografía prescriptiva nacional que apunta a las correcciones de habla con el fin de mejorar la educación en un país. Ejemplos de ello son Correcciones de defectos de lenguaje, para el uso de las escuelas primarias del Perú (1874) de Miguel Riofrío y especialmente el Diccionario de chilenismos ${ }^{3}$. Otro elemento que se reelaboró en una situación de formación nacional fue la inclinación enciclopédica que el registro del léxico americano había mostrado desde mucho antes del siglo XIX y que tenía como finalidad básicamente la explicación de términos de realia o -en una forma un tanto más compleja- la evangelización. En la lexicografía que revisamos, se supera este paradigma y se apunta a objetivos identitarios más amplios.

\footnotetext{
Tampoco Arona escapa a esta corriente y se refiere con frecuencia a procesos de corrupción (lo que en la época se puede entender más como transformaciones), pérdida y degradación dentro del habla peruana, aunque no hace ninguna referencia directa a la educación. Innumerables ejemplos de ello se pueden encontrar a lo largo de sus Observaciones generales previas al cuerpo del diccionario; en este, por el contrario, encontramos muy pocos casos y en ellos se muestra una actitud bastante menos crítica.
} 


\section{EL DISCURSO LEXICOGRÁFICO HISPANOAMERICANO DEL SIGLO XIX}

El estudio del discurso, en términos generales y salvando la gran amplitud de perspectivas desde las que se lleva a cabo, se plantea en primer lugar la determinación y descripción de sus dimensiones y estructuras. El interés de los investigadores no se restringe, sin embargo, a estos elementos, sino que también se presta atención, muchas veces de manera central, al aspecto social del discurso, entendido aquel como la relación dialéctica entre el discurso y la sociedad concreta en la que se genera ${ }^{4}$. En un nivel concreto, esto último significa que en el discurso -especialmente en aquel de las elites-se repiten y se refuerzan modelos ya establecidos de relaciones sociales, y se ofrecen otros nuevos que se quieren imponer. Dicho de otro modo, se asume en este orden de ideas que las relaciones de poder o de dominación en una sociedad tiene un fuerte componente discursivo, cuyo análisis escapa al campo puramente lingüístico. Un análisis crítico del discurso no solo describe esta situación de manera neutra, sino que además pone de relieve la relación existente entre el discurso y personas de carne y hueso en situaciones reales y concretas de convivencia social, y llega a tomar posición frente a ellas, alertando del peligro que supone la filtración en un determinado discurso de elementos ideológicos que perpetúan o buscan perpetuar formas sociales de dominación.

Desde esta perspectiva de análisis, en el caso de los diccionarios elaborados en un momento de formación nacional resulta necesario profundizar en algunos aspectos fundamentales. El primero de ellos lo constituye el dominio que se ejerce sobre el discurso. Así, se tienen que poner en primer plano, por un lado, el hecho de que los autores se arrogan la facultad de establecer y describir el habla correspondiente, y, por otro, la manera misma en que lo hacen, cuestiones sobre las que normalmente no se reflexiona y que ni se describen ni interpretan, aceptando su ocurrencia de manera natural. Mucho más importante es señalar un hecho recurrente en estas primeras obras: el paso de un ámbito filológico, en el que la autoridad del autor puede aceptarse, a uno mucho más amplio en el que este se permite comentar cuestiones centrales de la sociedad en la que vive. En otras palabras: el dominio ganado a partir de la cuestión filológica autoriza de cierta manera

4 La bibliografía sobre el estudio del discurso es amplísima; aquí basta con mencionar a van Dijk (2000a) y (2000b). 
al lexicógrafo hispanoamericano del siglo XIX a referirse también a temas sociales. Aquí no se tiene que perder de vista, sin embargo, que este paso - que hoy día resultaría forzado- era bastante normal en una época en la que era común la participación política de los intelectuales. No obstante, se trata de un aspecto determinante en la evaluación que estas obras merecen, porque conlleva precisamente un peligro del que un análisis crítico quiere alertar: si asumimos que los primeros lexicógrafos pertenecen a la elite cultural y económica de la sociedad postindependentista - en concreto, los criollos que heredan la administración colonial y el poder coercitivo-, está claro que los modelos que repetirán y difundirán a través de sus obras estarán claramente marcados por un sesgo ideológico propicio para ella.

\subsection{El DISCURSO LEXICOGRÁFICO HISPANOAMERICANO DEL SIGLO XIX COMO UN TIPO DE DISCURSO}

Emprender un análisis que se preocupe por la forma en que se expresan a través del discurso lexicográfico hispanoamericano los procesos y las estructuras sociales y culturales del siglo XIX independiente parte de la premisa de que existe una unidad discursiva entrevista a través de las diferentes obras individuales. Si bien en estas se pueden distinguir diversos objetivos específicos, es posible determinar claramente tal unidad a partir, en principio, de factores externos claramente reconocibles y que ya hemos ido apuntando: en el plano histórico, la recién ganada independencia pero de fuerte legado colonial; en el científico, la preocupación por el devenir de la lengua española en la América poscolonial. En cuanto a una disposición interna, esta unidad se caracteriza además por los siguientes elementos:

a) La descripción, no siempre exclusivamente en términos lingüísticos, del español de un determinado país y de sus peculiaridades frente a una norma general o penisular por parte de la elite culta de las sociedades hispanoamericanas decimonónicas. La pertenencia a esta elite, por cierto y como veremos más adelante, no es de ninguna manera un detalle supefluo. Significativa resulta, por ahora, la clara conciencia que los autores tienen de pertenecer a una corriente lexicográfica definida, la de los provincialógrafos de América -como dice Arona-, y que se hace explícita normalmente en las palabras de presentación de cada obra.

b) La presuposición de un grupo humano relativamente homogéneo identificado con un Estado (por ejemplo, los peruanos o los 
chilenos), cuya habla se describe como relativamente uniforme, de tal manera que, conscientemente o no, se participa en un proceso de construcción nacional. Tal identificación unívoca resulta ser en esencia una construcción discursiva que no se corresponde de forma necesaria con la realidad de los hechos, esto es, la existencia tanto de distintas sociedad y hablas dentro de un país. En los casos en los que se alude directamente a sociedades y hablas marginales, se acentúa con determinación esta última característica.

c) El contraste propuesto entre diferentes hablas hispanas y también entre las sociedades correspondientes (que corresponden, a su vez, a los diferentes países).

d) La forma lexicográfica de los textos, bastante alejada de las normas y pautas establecidas por la lexicografía al uso en otras latitudes, especialmente en Europa, que los autores conocían muy bien. Mientras que para un estudio filológico es ciertamente interesante describir este desapego a una técnica lexicográfica determinada en favor de un estilo más bien periodístico, en nuestro caso debemos reparar en que precisamente gracias a este estilo la subjetividad del autor se hace bastante más visible. Esto deja la puerta abierta a que el autor rebase el ámbito filológico y que llegue a tratar cuestiones sociales, aunque el solo título de diccionario o de obra filológica no lo prevea, lo que tiene finalmente importantes consecuencias en la recepción de la obra por parte de la sociedad.

e) El carácter dirimente mucho más que solo descriptivo de la opinión del autor, tanto en cuestiones lingüísticas, en principio, como también en cuestiones sociales.

f) Una alta capacidad de difusión y de asimilación. La palabra escrita y publicada juega un papel esencial en la aceptación y popularización de los juicios expresados a través del discurso. La posesión del medio -el registro escrito como su edición e impresión- por parte de los autores constituye una muestra y un uso claros del poder social por parte de la elite culta. 


\section{REPRESENTACIONES SOCIALES}

Antes de pasar a la lectura de los diccionarios que revisamos, vale la pena recordar una cuestión histórica elemental: la sucesión de los diferentes estadios por los que atravesó el continente desde finales del siglo XVIII hasta la plena instauración de los Estados actuales en un sistema republicano no fue la misma que podríamos encontrar en otros lugares del planeta.

En principio, no nos encontramos aquí ante la evolución de un sentimiento nacional que desencadena la independencia de España. Por el contrario, es la caída de la metrópoli debido a la invasión francesa la que pone en cuestionamiento en ámbitos criollos y tras un primer momento de clara fidelidad la unidad de las colonias con la corona y la legitimidad de aquella. Hay que tener en cuenta, además, que en cuanto a aspectos comerciales y económicos, incluso sociales, había una clara diferencia entre la postura de los criollos en determinadas zonas céntricas de larga tradición colonial, como Lima, y en zonas periféricas, de tal manera que el sentimiento independentista -además de otras razones, como el componente poblacional, por ejemplono podía ser el mismo. La independencia constituyó, así, un paso histórico con consecuencias más administrativas - la toma del poder económico y coercitivo por parte de las elites criollas-, que de reconocimiento identitario; de hecho, elementos tan esenciales como la religión y la lengua, incluso los rasgos étnicos, no funcionaron como diferenciadores entre los miembros de tales elites y los peninsulares 5 .

El final de las guerras de independencia dio paso a una formación del Estado -sobre una base social reducida y, en general, excluyente- que debía consolidar el cambio político-administrativo y, a la vez, determinar con claridad componentes que fueran comunes a un país pero que los distinguiera del resto. Esta es la razón por la que comienza una larga época de producción de elementos identitarios, desde símbolos de la patria hasta

5 En contra de lo dicho en este párrafo, por mucho tiempo la historiografía hispanoamericana partió de la asunción contraria, la de la existencia de un espíritu nacional que habría desencadenado la independencia. Sobre esta confusión, dice Chiaramonte: "Se trata, en suma, de las derivaciones aún vigentes del criterio de proyectar sobre el momento de la Independencia una realidad inexistente, las nacionalidades correspondientes a cada uno de los actuales países iberoamericanos, y en virtud de un concepto, el de nacionalidad, también inexistente entonces, al menos en el uso hoy habitual. Un concepto que se impondría más tarde, paralelamente a la difusión del Romanticismo, y que en adelante ocuparía lugar central en el imaginario de los pueblos iberoamericanos y en la voluntad nacionalizadora de los historiadores" (Chiaramonte 1997: 145). 
manuales de historia o geografía, pasando además por uno de los elementos más prototípicos, la literatura ${ }^{6}$. Desde este punto de vista, resulta claro el papel que jugaron los diccionarios de provincialismos y el alcance simbólico que tuvieron, muchas veces olvidado por la historiografía actual.

Con este telón de fondo, identificaremos y describiremos a continuación las representaciones sociales más importantes en las dos obras lexicográficas prototípicas del período que estudiamos, la de Zorobabel Rodríguez y la de Juan de Arona. Planteamos para ello dos planos distintos: aquel en que se representan elementos políticos y aquel en que se representan determinados grupos humanos del país. En el primer caso, se evalúa de qué manera se evidencia en los textos lexicográficos el proceso de establecimiento de una determinada forma de gobierno y en qué medida el autor lo comenta y lo interpreta. En el segundo, la manera en que aquel se posiciona desde el punto de vista lingüístico pero también social frente a tales grupos humanos. En ambos casos, resulta esencial no perder de vista que si bien se analizan autores y textos individuales, la vitalidad del discurso con el que nos encontramos goza de un alcance social bastante mayor.

\subsection{LA IMPRONTA POLÍTICA ${ }^{7}$}

Uno de los elementos definidores del siglo XIX hispanoamericano lo constituye el establecimiento del sistema político en los países recién formados. Como se sabe, este proceso se vio interrumpido repetidas veces debido a guerras civiles que enfrentaban a grupos de poder locales - organizados a partir de caudillismos-, de fuerza creciente desde la caída del gobierno colonial central y el desplazamiento de lealtades a falta de un rey. En el plano de las ideas políticas, sin embargo, es posible apreciar la fuerte presencia del pensamiento liberal, proveniente en gran medida de Cádiz, que había marcado la independencia y que intentaba dirigir, en una lucha frontal contra el pensamiento conservador, la constitución política hispanoamericana, si bien sin prestar mucha atención a la situación real de la sociedad y ajeno al hecho de que no ocurría una transformación profunda

\footnotetext{
6 Ver, por ejemplo, Burucua y Campagne (1994) y para el caso peruano, los ensayos de McEvoy (1999). Todo lo anterior se corresponde con una dicotomía ya clásica en la historiografía: identidad política/identidad cultural. Como decimos, en nuestro caso la identidad cultural se afianzó solo a partir de establecerse la primera; ver Guerra (2003). Sobre la formación del Estado nacional latinoamericano, ver Annino (1994) y (2003).

7 El tema de este apartado se desarrolla con mayor detenimiento en Huisa (2013).
} 
de los medios de producción ${ }^{8}$. En un nivel historiográfico, es productivo, no obstante, superar esta clásica confrontación entre el pensamiento liberal y el conservador y, más bien, asumir la existencia de un categoría operativa, el republicanismo, para entender el devenir político hispanoamericano del $\mathrm{XIX}^{9}$.

Volviendo al proceso formativo de la época y a nuestro tema, salta a la vista de un lector atento que las formas en que aquel se imprime en las dos obras lexicográficas que ahora tomamos como casos de estudio es distinta, lo cual es en gran parte resultado del diferente nivel en el que se encontraban ambos países en la consolidación de la república: mientras que en Chile se puede hablar hacia el momento de la elaboración de estos diccionarios de un Estado en un proceso adelantado de formación (basta recordar, como ejemplo, el papel organizativo que se le da a Diego Portales), el proceso peruano iba un tanto retrasado debido a las diferentes guerras civiles y a la importancia de los caudillos locales (Manuel Pardo, la figura más relevante de la proceso republicano en Perú, cobra mayor importancia solo entre las décadas del 60 y del 70).

Así, vemos que Zorobabel Rodríguez alude directamente y desde un primer momento al sistema republicano establecido en el país y corporeizado en el Presidente al decir en su dedicatoria: "El autor de este libro tiene a honra dedicarlo respetuosamente al Presidente de la República, para quien esté reservada la gloria de promulgar la lei que establezca en Chile la libertad de enseñanza i de profesiones" (VI). La consabida postura política del autor, a caballo entre el conservadurismo y el liberalismo, tanto en cuestiones políticas y sociales como especialmente económicas puede explicar el papel de la ley en cuestión en los debates políticos ${ }^{10}$. Aquí resulta interesante también -si queremos ver la manera como se manifiesta en el diccionario

8 Esto último puede sintetizarse en el concepto de modernización tradicionalista, con el cual se explicaría el proceso peruano tras la independencia: "La modernización tradicionalista es una verdadera modernización; lo que significa que introduce elementos nuevos dentro de la sociedad tradicional y la transforma. Pero, al mismo tiempo, esta sociedad no se desprende de ciertos elementos antiguos o "tradicionales" que permanecen como aspectos nucleares, en torno a los cuales se organiza la modernización. En todo proceso de modernización es evidente que subsisten muchos elementos del pasado. Pero en la modernización tradicionalista los elementos que subsisten no son relegados a la periferia del proceso como rezagos de un pasado que desaparece gradualmente sino que se constituyen en los elementos centrales del proceso" (de Trazegnies 1987: 106).

9 Para el caso peruano, ver McEvoy (1997) y (2001).

10 Sobre esto, ver Correa (1997) y (1999). Aquí queda claro lo dicho líneas arribas: el comportamiento político de Rodríguez se explica mejor por un espíritu republicanista que a partir de una cerrada clasificación liberal/conservador. 
el devenir político de aquel entonces- que, ya muy entrado el siglo XIX las elites hispanoamericanas todavía continuaran haciendo hincapié en la idea ilustrada de la educación como medio de progreso y que todavía fuera una espinosa tarea pendiente para ella determinar el papel que debía cumplir el Estado en esa cuestión. En torno de esta, de hecho, gira de forma determinante la concepción y la elaboración de la obra. Rodríguez no deja de señalar sin ninguna reserva la necesidad de la buena enseñanza de la gramática en una época de formación nacional, criticando severamente la situación actual: "La incorrección con que en Chile se habla i escribe la lengua española es un mal tan jeneralmente reconocido como justamente deplorado" (VII). Digamos de paso en este momento que el caso de Arona es radicalmente distinto: ni la educación ni un supuesto telón de fondo republicano y de formación nacional juegan algún papel explícito en la concepción y elaboración de su obra. Se refiere a su trabajo, más bien, como un estudio filológico que tiene como fin encontrar los verdaderos peruanismos en el habla peruana ${ }^{11}$.

Tras una lectura atenta, resulta evidente que la representación del componente político de la sociedad que nos muestra Rodríguez tiene una fuerte carga institucional. Esta imagen de un sistema dentro del que se desarrolla la vida social y política atraviesa varios artículos del diccionario. Son recurrentes algunos elementos sintomáticos: definiciones de conceptos políticos, por ejemplo pelucón ('conservador') y pipiolo ('liberal'); claras referencias a la formación nacional, por ejemplo, "nuestra sociedad recien salida de la crisálida" (s. v. capuchino, -a); la apelación constante a la naturaleza republicana del país y del continente, por ejemplo, "la América española y republicana" (s. v. bagual), "todas las repúblicas latinoamericanas" (s. v. rocambor) o "la capital de la república" (s. v. calduda); etc.

Como es bastante común en la lexicografía hispanoamericana decimonónica se echa mano aquí también de categorías políticas -en una especie de símil-, para adentrarse en temas puramente lexicológicos. Uno de los casos más prototípicos - dicho sea de paso-, es el de Ricardo Palma, para quien la determinación del uso de las unidades léxicas debe ser una consecuencia de la democracia popular antes que de la soberana imposición académica. En la obra de Rodríguez también ocurre esto, si bien en una intensidad bastante menor, al decir varias veces:

11 Interesante es, por cierto, -como veremos más adelante- que este objetivo filológico apunta sobre todo a demostrar la fuerte raíz castiza que los peruanismos tienen, lo que también tiene consecuencias en las representaciones sociales que el diccionario ofrece. 
¡I vaya que el soberano pueblo tiene razon contra el señor Vicuña, i que está bien dicho los Carreras! (s. v. apellidos en plural).

Sea de ello lo que fuere es lo cierto que en la América republicana, donde somos demasiado demócratas para hablar de plebeyos, somos bastante caballeros para no tener un vocablo que nos permita designar a las personas de baja alcurnia sin acudir a las sutiles distinciones de indios, mestizos, zambos i [sic] mulatos (s. v. chino, a, amento, ero, era, ito, a).

Es éste un provincialismo americano de corrientísimo uso, que no ha tenido sinembargo [sic] todavía el honor de ser reconocido por la Academia, como si la ilustre corporación tuviese empeño en seguir con las nuevas palabras de estos países, la misma política pachorruda que el gobierno de Madrid sigue con los nuevos estados que surjieron [sic] de la guerra de independencia. ¡Solo en este año ha reconocido la de la república de Venezuela! (s. v. chancaca).

La imagen de la situación política que nos ofrece Arona es de otro signo y su elaboración es más compleja: la consecución del objetivo filológico mencionado lo lleva sistemáticamente y casi sin solución de continuidad a que exprese su opinión -duramente crítica e irónica-sobre el proceso formativo republicano. La presentación de la situación lingüística hispanoamericana en sus Observaciones generales es un ejemplo perfecto:

Si nos figuramos en nuestra mente el aspecto del idioma castellano en la America española, nos parecerá ver el vasto lecho de un océano exhausto. Allí hay de todas los naufrajios; riquezas completas, riquezas truncas; séries de despojos hermosos y por acaso bien ordenados; montones de restos informes, heterogéneos, revueltos; lo arcaico dándose de coces con lo flamante; resultado todo de los dos grandes naufrajios, el de la civilización indíjena que desapareció hace tres siglos con la conquista, y el de la española que se perdió al comenzar el presente con la emancipación; y de los pequeños naufragios poco menos que diarios, de estas nuevas Repúblicas, fiscales, sociales, políticos, morales, etnográficos, con lo que ha acabado de perderse lo poco salvado, y se ha aumentado la confusión (XXIV-XXV).

Esta imagen decadente y criticable es una constante en la obra. En la Introducción, que recoge un texto publicado en la prensa ya en 1870, dice con poca sutileza:

El español, que está lejos de ser la más culta de las lenguas modernas, ha sido más irrepestuoso que el inglés y el francés, y hecho un verdadero republicano, ha roto con el pasado ahuyentado de su ortografía la $t h$, la 
$p h$, la $y$ griega vocal, en las voces de origen griego, y hasta la $x$ y el trans, que hoy son casi siempre $s$ y tras (XLIII).

También en la representación de los agentes políticos, la representación del sistema es distinta en cada caso. Mientras que en Rodríguez la preocupación lexicográfica está en primer plano y controla de cierta manera la subjetividad del autor, en Arona la crítica al sistema, esta especie de antirrepublicanismo, se cuela a cada momento, de tal forma que la definición lexicográfica es de tipo subjetivo. Veamos, por último, un ejemplo de cada uno:

Aun cuando lo mejor en materia de apodos es no usarlos, ya que la mala costumbre subsiste, es preciso reconocer que los de pipiolo i pelucon tenían sobre los que en la actualidad usan los guerrilleros de la política la doble ventaja de ser nacionales i expresivos (s. v. pipiolo, ismo, aje).

[El capitulero es] El hombre de las elecciones populares, el que dispone de la gente (cuadrillas y turbas) y de los cubiletes para sacar avante [sic] á un candidato á la diputación ó á la presidencia de la República.

El capitulero es unas veces de segundo órden, y entonces como tipo social gira entre los galleros y mozos crudos. Otras veces es de mejor alcurnia, y una vocación irresistible ó reveces de fortuna lo arrastran á esa especulación, porque bien visto no es más. Y así como el actor á fuerza de interpretar al autor se ha él mismo autor dramático; así como el boticario de tanto manosear recetas se lanza á espedirlas y se convierte en médico, y asi como es raro el cajista que degenera en periodista, llega un día en que el capitulero se dice anch 'io sono politico; y como toda la enciclopedia y carrera universitaria que se necesita para figurar en este ramo es habilidad práctica, el capitulero no tarda en ser uno de nuestros prestigiosos (s. v. capitulero).

Las diferencias entre las representaciones políticas que ambos diccionarios nos ofrecen son bastante claras y -según nuestro parecer- constituyen una manifestación del punto en que se encontraba cada elite en el proceso de constitución e implantación del modelo de gobierno.

\subsection{GRUPOS hUMANOS EN LA SOCIEDAD}

La representación de los distintos grupos humanos en el país correspondiente es un elemento muy visible en esta primera lexicografía hispanoamericana, si bien en distintos grados a partir de cuestiones idiosincrásicas, como ocurre en los dos casos que estamos revisando. Insistamos en la idea que dirige nuestras reflexiones aquí: está claro que el panorama social que estas obras 
filológicas muestran no es de ninguna manera aquel que se corresponde fielmente con los hechos reales -lo que por cierto es casi imposible, incluso si nos enfrentáramos a obras documentales-, sino que es resultado de la mirada desde una determinada perspectiva social e ideológica. En este orden de ideas, la mediación que constituye el discurso de los lexicógrafos -cuya capacidad de generar, afianzar y difundir representaciones sociales podemos observar y evaluar- es determinante, porque a través de tales representaciones sociales accedemos al imaginario de la elite criolla decimonónica.

Veamos dos términos definitorios en este plano. Por un lado, roto en el diccionario chileno:

Esta palabra no es propiamente un chilenismo, porque una de sus acepciones castizas es andrajoso, zarrapastroso.

Téngase, sí, como una peculiaridad de nuestro uso el servirnos de aquella voz para designar a la jente de última clase, a la misma cuyos individuos son llamados cholos en el Perú, i léperos en Méjico (s. v. roto).

y cholo en el peruano:

Una de las muchas castas que infestan el Perú; es el resultado del cruzamiento entre el blanco y el indio. El cholo es tan peculiar á la costa, como el indio á la sierra; y aunque uno y otro se suelen encontrar en una y otra, no están allí más que de paso, suspirando por alzar el vuelo; el indio por volverse á sus punas y á su llama, y el cholo por bajar á la costa, á ser diputado, magistrado ó presidente de la República; porque, sin duda por exageración democrática, los primeros puestos de nuestro escenario político han estado ocupados con frecuencia por cholazos de tomo y lomo. Es pues un grandísimo error creer que con decir cholo está designado el pueblo peruano, como lo están en Méjico y Chile cuando se dice el lépero y el roto. El cholo aquí no es más que un individuo del pueblo, o de la sociedad, o de la política (s. v. cholo).

Este caso se debe explicar apelando a la disparidad entre ambas obras en cuanto a la carga subjetiva que presenta el discurso lexicográfico. En Rodríguez, si bien esta no está complemente ausente -fijémonos en la asunción indiscutible de pertenencia que no se explica-, es evidente que lo que ocupa el primer plano es la materia filológica o por lo menos lexicográfica del artículo, esto es, la explicación del uso y la designación, y la presentación de equivalentes. En Arona, por el contrario, la preocupación filológica o lexicográfica es prácticamente inexistente y el artículo resulta ser una descripción enteramente subjetiva. Notemos, de paso, la alusión consabida al sistema republicano. 
Sugerente resulta también plantear la cuestión de la manera en que se establece una relación directa entre la voz del autor, también entendida como la de una entidad más amplia, y los grupos humanos a los que se refiere. Rodríguez utiliza sistemáticamente el posesivo para referirse a grupos distintos al suyo: "[...] pero no lo es atrasarse en el sentido que le dan nuestros guasos en frases como éstas: [...]" (s. v. atrasarse), "Para concluir solo agregaremos haber oido mas de una vez a nuestros guasos i gafianes usar botado en el sentido de[...]" (s. v. botado), "Comer maqui i sacar huira, es un adajio mui expresivo que usan nuestros guasos para indicar que [...]" (s. v. huira,o), "En casos tales suelen decir nuestros rotos que ha visto burros negros" (s. v. burros negros (verlos)), "Uno de los innumerables verbos con que nuestros rotos llaman su distraccion favorita de embriagarse" (s. v. curarse), etc. Esta forma retórica de apropiación del otro -lo que esconde muchas veces un trato de inferior o de menor de edad- es un fenómeno bastante usual incluso hoy en día y coincide con marcadas diferencias sociales que consciente o inconscientemente se resaltan. En nuestro caso, no es pertinente una interpretación mayor; más bien, tengamos en cuenta sobre todo la cuestión concreta de la apelación a este recurso retórico en el tipo de discurso que estudiamos y las consecuencias de su recurrencia en la construcción de la representación de estos grupos sociales.

Este comportamiento es infrecuente en el caso de Arona y los ejemplos son contados: "Si algunas de nuestras cholas ó zambas viniendo á caballo del campo se atan el sombrero, con un pañuelo para que no se les vuele, llamarémos á eso barbiquejo por analogía solamente" (s. v. barbiquejo) y "Es uno de los mil modos que nuestra plebe tiene de lucir la desaforada libertad y la animal felicidad de que rebosa" (s. v. quimba). Encontramos, más bien, un claro distanciamiento desde un nosotros -actualizado también por otros pronombres personales y posesivos- bastante definido ${ }^{12}$ que se corresponde con el habla que la obra describe y con la representación social de la elite criolla. Esta diferenciación entre nosotros y otras instancias es un reflejo de la coincidencia de las diferencias sociales y económicas con las étnicas en el Perú decimonónico, y que tiene como base aquella distinción entre república de indios y de españoles sobre la que estaba organizada la administración colonial. De esta forma, en el discurso de Arona categorías como los indios o los negros, por ejemplo, siempre forma parte de los otros. Dicho sea de paso, en el caso de Zorobabel Rodríguez casi nunca se apela

12 Fuera, claro, del plural de autoría y de la autodesignación como hispanoamericano o hablante del español americano, especialmente frente a los peninsulares, elementos compartidos con la obra chilena. 
a estas identificaciones étnicas, de tal manera que se ofrece una imagen de unidad, probablemente consecuencia de la realidad de los hechos - es posible decir que la complejidad étnica chilena es mucho menor que la peruana-, pero de la cual todavía es válido dudar, en cuanto se trata finalmente de una representación que se pone sobre la mesa a través del discurso.

Volvamos al distanciamiento impuesto por Arona desde un nosotros que actúa como categoría operativa en su discurso y se identifica sin ningún reparo con los peruanos por antonomasia:

Los peruanos de hoy, que más ó ménos directamente recibimos educación europea, y que por la sangre, el idioma y los nombres de familia nos sentimos atraídos al viejo mundo y nos amamantamos en el amor de Grecia y Roma, mirando con indiferencia, con frialdad y hasta con desden la civilización incaíca, que en realidad no es mas que una tradición, debemos advertir que así como á los negros racionales les ofende el color, asi esa civilización que hoy menospreciamos no tuvo más baldon que el haber carecido de "letras humanas", como diría Garcilaso (s. v. incas).

Este distanciamiento también se basa en criterios geográficos: el discurso se ubica en Lima y desde ella se hace referencia a otras zonas del país, de lo cual se generan dos claras dicotomías sobre las que giran casi todas las afirmaciones del autor sobre el español peruano y la sociedad: Lima/Arequipa (la segunda ciudad en importancia, por lo menos en la obra) y costa/sierra, como se ve en los siguientes artículos:

Aguatera--Arequipa. Lo que nosotros llamamos en Lima la tinajera, y el Diccionario, el tinajero.-Aguatero por aguador es comun en Arequipa y Tacna. En Lima no usamos la desinencia tero; á no ser en la palabra leñatero, que así decimos por leñador, vocablo que parecería pluscuam culto en boca nuestra.

Cacharpari.-Fiesta nocturna, jarana ó festejo que se dá en obséquio de alguno que parte al dia siguiente, cuando no es el mismo próximo viajero el que hace de Anfitrión. Esta costumbre como el nombre lo indica nos viene de la sierra, en donde es mucho mas corriente que entre nosotros.

La perspectiva del autor desde la que observa y describe la situación peruana da paso también, escapando de los meros hechos lingüísticos, a una descripción racial:

Ananáy!.-Arequipa. Ay! De abatimiento y enfermedad. La frecuencia del sonido en ay y el de la $l l$ mojada ó liquida dan á la lengua quichua una gran expresion de ternura, que por otra parte parece reflejar la eterna sumisión de carácter y la eterna sujecion social de la raza que la ha hablado [...]. 
Está claro que aquí nos encontramos con la consolidación y difusión de una percepción determinada -que se basa en un proceso de racialización $^{13}$ - que genera o mantiene una situación de dominación. Veamos aquí, por ejemplo, el consabido sabor paternalista que no escapa a este tipo de percepciones: "[...] que las más de las veces es una vasija para beber, como si aquellos buenos indios hubieran querido mezclar lo útil á lo agradable"(s. v. huaca).

Por último, vale la pena echarle una mirada a la forma como nuestros lexicógrafos se enfrentaron a la situación del contacto del español con las lenguas indígenas y cuáles son las repercusiones en las representaciones sociales. En el caso de Rodríguez, el papel que cumple el araucano está bastante claro y no se sale de los límites impuestos por el objetivo lexicológico y lexicográfico: el préstamo al español chileno y su asimilación a este. La imagen del español chileno, entonces, se ve grabada fuertemente por estos procesos y no se hace patente ningún tipo de conflicto, como en el siguiente artículo: "Del araucano caru o cari, verde. Al, adoptar nosotros esta palabra indíjena alteramos su significado, pues llamamos cari a la oveja de lana parda, o albarazada, i alas mantas i ponchos que de ella se tejen" (s. v. cari) y en fragmento del Prólogo:

Así ya en adelante no tendrá disculpa el escritor que, como casi todos hasta ahora, sin otro guia que su instinto i juzgando de los vocablos por el aspecto, subraye i haga publicar en bastardilla como provinciales muchas voces que son de la mas lejitima cepa española, i vice-versa, dé paso franco, como si fuesen castizas, a otras que vienen en linea recta del quichua o del araucano o de ninguna parte, porque son disparates de tomo i lomo (IX).

En el caso peruano, la postura que nuestro autor tiene frente a las lenguas indígenas es clara. Veamos solamente un caso prototípico:

Aimará.- Una de las dos grandes lenguas (la otra era el quíchua o quéchua) que hablaban los indígenas peruanos á la llegada de los

13 En Andrade (2008) y (2009) se ha hecho hincapié en el papel racializador -especialmente en lo referente al cuerpo- de las definiciones de Arona, no solo respecto a los indios sino también a los negros. Comparemos, por ejemplo: "Cholo.-Una de las muchas castas que infestan el Perú; es el resultado del cruzamiento entre blanco y negro. [...]"; "Sacalagua-Nombre de una de las infinitísimas castas que pueblan la costa del Perú. El ó la sacalagua es blanco, rubio y de ojos azules; pero [...]". 
conquistadores españoles. Los únicos indios que hoy siguen hablando el aymará son los de Bolivia, ó los limítrofes del Perú ${ }^{14}$.

Notemos el uso tanto del pasado imperfecto, era y hablaban, que constatan que la situación del presente de la obra es opuesta a la que el artículo menciona, y el adjetivo únicos para los hablantes actuales, aun cuando en una población de aproximadamente dos millones de habitantes en el territorio peruano, el número de hablantes de lenguas indígenas no era porcentualmente insignificante. Notemos, además, que la nueva configuración política a partir de los Estados recién creados se superpone a la unidad de una etnia de mucho mayor pasado. De cualquiera manera, no nos debe sorprender que en el discurso de la obra las lenguas indígenas jueguen un papel bastante marginal, lo que constituye un correlato casi natural del ideario del autor, para quien tanto el español como las fuertes raíces castizas del hablado en Lima ocupan un primerísimo plano.

\section{CONCLUSIÓN}

La ampliación del punto de vista desde el cual se evalúan los orígenes de la lexicografía hispanoamericana, al asumir que las obras correspondientes -antes que meros productos filológicos- resultan ser manifestaciones de una determinada época histórica del continente, lleva a una descripción y a un análisis más profundo del fenómeno. En ese sentido, resulta necesario prestarle atención al papel que juega la formación nacional -en cuanto constitución política y proceso de formación identitaria-, tanto en la elaboración como en la recepción de ellas. Vemos, a partir de este planteamiento, que el discurso lexicográfico al que nos enfrentamos ofrece un cúmulo de representaciones sociales provenientes de las elites -en el plano político como en el puramente social-que se afianzan y se difunden, proceso en el que muchas veces no se repara, precisamente porque se asume que la obra se mantiene dentro de los márgenes de una contribución científica.

14 Se debe considerar también el siguiente artículo: "Chinchaysuyo.-Un gran dialecto, que, como las lenguas quíchua y aymará, se hablaba en el Perú en los dias de la conquista. [...]". Más tarde, Arona presenta otro artículo, ahora encabezado por aymará, que vale la pena revisar. 


\section{REFERENCIAS BIBLIOGRÁFICAS}

ANDRADE, LuIs. 2008. Léxico y racialización en Juan de Arona. Ponencia presentada al VII Coloquio de Lexicología y Lexicografía, organizado por la Facultad de Letras y Ciencias Humanas y la Escuela Académico-Profesional de Lingüística de la Universidad Nacional Mayor de San Marcos. Lima, Perú.

2009. El cuerpo de los otros en Juan de Arona. Ponencia presentada en el IV Congreso Internacional de Lexicología y Lexicografía en Homenaje a Juan de Arona, organizado por la Academia Peruana de la Lengua, Lima, Perú.

Annino, Antonio, Luis Castro y François-Xavier Guerra (eds.). 1994. De los imperios a las naciones: Iberoamérica. Zaragoza: Ibercaja.

Annino, Antonio y François-Xavier Guerra (eds.). 2003. Inventando la Nación: Iberoamérica siglo XIX. México, D.F.: Fondo de Cultura Económica.

Arona, Juan de [seudónimo de Pedro Paz Soldán y Unanue]. s.f. [1883-84]. Diccionario de peruanismos. Ensayo Filológico. Lima: Librería Francesa Científica J. Galland [en línea]. Disponible en https://archive.org/stream/diccionariodepe00arongoog\#page/n5/ mode/2up [Consulta 10/05/2014].

Burucua, José E. y Fabián A. Campagne. 1994. Los países del Cono Sur. En Antonio Annino, Luis Castro y François-Xavier Guerra (eds.). De los imperios a las naciones: Iberoamérica, pp. 349-381. Zaragoza: Ibercaja.

Chiaramonte, José Carlos. 1997. La formación de los estados en Iberoamérica. Boletín del Instituto de Historia Argentina y Americana Dr. Emilio Ravignani 15: 143-165.

Correa, Sofía. 1997. Zorobabel Rodríguez: Católico liberal. Estudios Públicos 66: 387-426. 1999. 'De nuestra inferioridad económica': Reflexiones sobre los límites del desarrollo capitalista chileno. Estudios Públicos 73: 401-430.

DE TRAZEgnies, Fernando. 1987. La genealogía del derecho peruano. Los juegos de trueques y préstamos. En Alberto Adrianzén (ed.). Pensamiento politico peruano, pp. 99-133. Lima: DESCO.

Guerra, François-Xavier. 2003. Las mutaciones de la identidad en la América hispánica. En Antonio Antonio y François-Xavier Guerra (eds.). Inventando la Nación: Iberoamérica siglo XIX, pp. 185-220. México,D.F.: Fondo de Cultura Económica.

Huisa Téllez, José Carlos. 2011. Estudio preliminar de Diccionario de Peruanismos. Ensayo filológico de Juan de Arona. Tesis para optar al grado de Doctor en Lingüística Aplicada (Romanística), Universidad de Augsburgo.

2013. La impronta política en la primera lexicografía hispanoamericana: republicanismo y antirrepublicanismo. Lexis 37 (2): 269-303.

Lara, Luis Fernando. 1990. Dimensiones de la lexicografía. A propósito del Diccionario del Español de México. México, D. F.: El Colegio de México.

McEvoy, CARMEN. 1997. La utopía republicana. Ideales y realidades en la formación de la cultura política peruana. Lima: Pontificia Universidad Católica del Perú.

1999. Forjando la nación: ensayos sobre historia republicana. Lima, Sewanee: Instituto Riva-Agüero (Pontificia Universidad Católica del Perú), The University of the South.

2001. Estudio preliminar. En Juan Espinosa. Diccionario Republicano para el pueblo (Edición de Carmen Mc Evoy), pp. 21-100. Lima, Sewanee: Pontificia Universidad Católica del Perú, The University of the South.

Riofrío, Miguel. 1874. Correcciones de defectos de lenguaje: para el uso de las escuelas primarias del Perú. Lima: Imprenta del Universo. 
Rodríguez, Zorobabel. 1875. Diccionario de Chilenismos. Santiago: Imprenta de "El Independiente".

VAN Dijk, Teun A. (Comp.). 2000a. El discurso como estructura y proceso. Estudios sobre el discurso I: Una introducción multidisciplinaria. Barcelona: Gedisa.

(Comp.). 2000b. El discurso como interacción social. Estudios sobre el discurso II. Barcelona: Gedisa. 